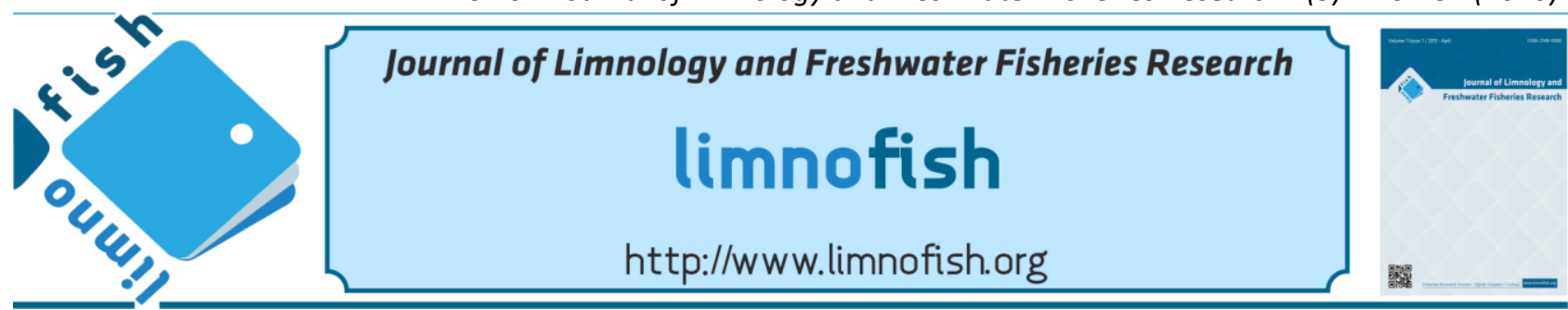

\title{
Kirmir Çayı (Sakarya Nehri)'ndaki Balık Türlerinin Biyoçeşitliliği
}

\author{
A. Şeref KORKMAZ ${ }^{1}$, Özge ZENCIR TANIR ${ }^{2, *}$ \\ ${ }^{1}$ Ankara Üniversitesi, Ziraat Fakültesi, Su Ürünleri Mühendisliği, 06110 Dışkapı-Ankara-Türkiye \\ ${ }^{2}$ Erzincan Üniversitesi, Kemah MeslekYüksekokulu, 24400 Kemah-Erzincan-Türkiye
}

\section{$\ddot{o z}$}

Bu araştırmada, Sakarya Nehri'nin önemli kolarından biri olan Kirmir Çayı'ndaki balık türlerinin bazı çeşitlilik indekslerinin incelenmesi amaçlanmıştır. Balık örnekleri Kasım 2006 - Kasım 2007 tarihleri arasında elektroşoker kullanılarak alınmıştır. Yapılan örneklemelerde 3 familyaya (Cyprinidae, Cobitidae ve Nemacheilidae) ait 9 tür; tatlısu kefali (Squalius pursakensis Hankó, 1925), biyıklı balık (Barbus escherichii Steindachner, 1897), siraz (Capoeta baliki Turan, Kottelat, Ekmekçi and Imamoğlu, 2006), saçaklı siraz (Capoeta sieboldii Steindachner, 1864), noktalı inci balığ1 (Alburnoides bipunctatus Bloch, 1782), kababurun (Chondrostoma angorense Elvira, 1987), sakarya incisi (Alburnus escherichii Steindachner, 1897), taşyiyen balığ1 (Cobitis simplicispina Hankó, 1925) ve çamur balığı (Oxynoemacheilus angorae Steindachner, 1897) tespit edilmiştir. A. escherichii toplam popülasyon içerisinde \% 28,71 ile en çok bulunan türdür. Çeşitlilik indekslerinden, Shannon-Wiener çeşitlilik indeksi $\left(H^{\prime}\right)$, Shannon-Wiener çeşitlilik indeksine dayalı eşitlik indeksi $\left(J^{\prime}\right)$, Simpson çesitlilik indeksi (1-D), Simpson indeksine dayalı eşitlik indeksi $\left(V^{\prime}\right)$ ve Simpson baskınlık indeksi $(D)$ hesaplanmıştır. Elde edilen ortalama indeks değerleri sırasıyla $1,67 \pm 0,12,0,77 \pm 0,06,0,76 \pm 0,03,0,86 \pm 0,04$ ve $0,61 \pm 0,07$ olarak bulunmuştur. IUCN (2014) Kırmızı Liste'ye göre; $S$. pursakensis, A. escherichii ve $O$. angorae asgari endişe (LC), B. escherichii ve $C$. sieboldii tehlike altında (EN), A. bipunctatus hassas (VU) ve $C$. angorense ve $C$. simplicispina ise kritik derecede tehlike altındaki (CR) türler olarak tespit edilmiştir. Çalışma alanında, türlerin devamlılığını tehdit eden en önemli unsurların çevresel kirlilik, tarımsal kirlilik, metal kirliliği, habitat kaybı ve kuraklık olduğu düşünülmektedir.
MAKALE BILGISI

\section{ARAŞTIRMA MAKALESI}

$\begin{array}{ll}\text { Geliş } & : 17.11 .2016 \\ \text { Düzeltme } & : 28.11 .2016 \\ \text { Kabul } & : 15.12 .2016 \\ \text { Yayım } & : 23.12 .2016\end{array}$

DOI: 10.17216/LimnoFish.267103

\section{* SORUMLU YAZAR}

zencir06@hotmail.com Tel : +904462266666 Faks : +904462266665

Anahtar kelimeler: Balık faunası, çeşitlilik, indeks, Kirmir Çayı

\section{Fish Species Biodiversity in Kirmir Stream of Sakarya River}

Abstract: In this study, it was aimed to determine some diversity indices of fish species in Kirmir Stream of Sakarya River, Central Anatolia Turkey. Fish samples were caught by electrofishing between November 2006 and November 2007. A total of 9 fish species representing 3 families Cyprinidae, Cobitidae and Nemacheilidae were recorded. Fish species identified are as follows: Sakarya chub (Squalius pursakensis Hankó, 1925), Ankara barbel (Barbus escherichii Steindachner, 1897), Sakarya barb (Capoeta baliki Turan, Kottelat, Ekmekçi and Imamoğlu, 2006), colchic khramulya (C. sieboldii Steindachner, 1864), schneider (Alburnoides bipunctatus Bloch, 1782), Ankara nase (Chondrostoma angorense Elvira, 1987), Sakarya bleak (Alburnus escherichii Steindachner, 1897), Sakarya spined loach (Cobitis simplicispina Hankó, 1925) and Angora loach (Oxynoemacheilus angorae Steindachner, 1897). A. escherichii was the most occurence species, constituting $28.77 \%$ of the total fishes. Shannon-Wiener diversity index $\left(H^{\prime}\right)$, evenness based on Shannon's index $\left(J^{\prime}\right)$, Simpson's diversity index (1-D), evenness based on Simpson's index $\left(V^{\prime}\right)$ and dominance index from diversity indices were calculated. The mean indices values were estimated as $1.67 \pm 0.12,0.77 \pm 0.06,0.76 \pm 0.03$, $0.86 \pm 0.04$ and $0.61 \pm 0.07$, respectively. $S$. pursakensis, $A$. escherichii and $O$. angorae, included on least concern (LC) species, $B$. escherichii and $C$. sieboldii endangered (EN) species, A. bipunctatus vulnerable (VU) species, $C$. angorense and $C$. simplicispina critically endangered (CR) species in the 2014 IUCN Red List of Threatened Species, were recorded in Turkey. In the study area, the most important factor threaten sustainability of the species is considered to be the environmental pollution, agricultural pollution, metal pollution, habitat loss and drought.

Keywords: Fish fauna, diversity, index, Kirmir Stream, Turkey 


\section{Giriş}

Biyolojik çeşitlilik birbirleriyle ilişki içerisinde olan canlı topluluklarının çeșitliliği olarak ifade edilebilir. Başka bir deyişle biyolojik çeşitlilik bir bölgedeki genlerin, bu genleri taşıyan türlerin, bu türleri barındıran ekosistemlerin ve bunları birbirine bağlayan olayların tamamını kapsar. Bu bağlamda çeşitlilik; genetik, tür, ekosistem ve ekolojik olay çeşitliliğini içine alan çok geniş bir kavramdır. Tür çeşitliliği, tüm türleri içine alan belirli bir bölgede bulunan türlerin sayısının çokluğudur (Erten 2004; Gülsoy ve Özkan 2008).

Çeşitlilik derecesinin sayısal bir değer olarak belirtilmesi ve farklı sistemlerin çeşitlilik derecelerinin istatistiksel olarak karşılaştırılabilmesi için çeșitlilik indekslerinin hesaplanması gerekir (Odum ve Barrett 2005). Shannon-Wiener çeşitlilik indeksi $\left(H^{\prime}\right)$, Shannon-Wiener çeşitlilik indeksine dayalı eşitlik indeksi-evenness $\left(J^{\prime}\right)$ ve Simpson indeksi istasyonlarda tür zenginliği ve bireylerin türler arasındaki dağılımı hakkında bilgi edinmek için en yaygın olarak kullanılan çeşitlilik indeksleridir (Jorgensen vd. 2005).

Sakarya Nehri ve Kirmir Çayı'nda yaşayan balıklar üzerine şimdiye kadar çeşitli araştırmalar yapılmıştır (Ölmez 1992; Solak vd. 1995; Y1lmaz vd. 1996; Benzer 2013; Kahraman vd. 2014). Ancak Kirmir Çayı'nın çeşitlilik indeksleri üzerine herhangi bir çalıșma bulunmamaktadır. Böylece yapılan bu çalışma ile Kirmir Çayı'ndaki balık türlerinin bazı çeşitlilik indekslerinin hesaplanması amaçlanmıştır. Ayrıca yapılacak diğer araştırmalarla karşılaştırma olanağı sağlayabilecek verilerin elde edilmesi de amaçlanmıştır.

\section{Materyal ve Metot}

Kirmir Çayı, Türkiye'nin İç Anadolu Bölgesi'nde 40-41 $1^{\circ}$ kuzey enlemleri ve $32-33^{\circ}$ doğu boylamları arasında yer alan yaklaşı 223.900 ha alan ve $806.106 \mathrm{~m}^{3}$ y1llik su potansiyeli ile Sakarya Nehri'nin önemli kollarından birisidir (Küçük ve Alpbaz 2008). Bu araştırma 3'er aylık periyotlarla Kasım 2006 - Kasım 2007 tarihleri arasında yürütülmüștür. Kirmir Çayı'nda tür çeşitliliğini belirlemek amaciyla 4 örnekleme istayonu (K1, K2, $\mathrm{K} 3$, K4) seçilmiştir. $\mathrm{Bu}$ örnekleme istasyonları detaylı bir arazi etüdü yapıldıktan sonra akarsuyu temsil edebilecek nitelikte seçilmiştir (Hankin 1984; Bohlin vd. 1989) (Şekil 1). 1. örnekleme istasyonu 5$10 \mathrm{~cm}$ çapında küçük taşlık, banklar yer yer ağaç köklü; 2. örnekleme istasyonu $20-30 \mathrm{~cm}$ çapında taşlık, banklar ağaçsız ve etrafı açık, az iri kayalık; 3 . örnekleme istasyonu 30-50-70 cm çapında taşlık, yer yer ağaçll, birikintili ve 4. örnekleme istasyonu ise etrafi sazlık, yer yer çakıllı ve $30-50 \mathrm{~cm}$ çapında büyük taşlık, 1-1,5 m çapında kayalıklardan oluşmaktadır.

Seçilen örnekleme istasyonlarında, araştırmanın balık materyali elektroşoker (500-700 watt, 2A, D.C) kullanılarak avlanmıştır. Avlamalar, alt ve üst sinırlar1 dügümden düğüme $10 \mathrm{~mm}$ göz açıklığında sabit ağlarla kapatılmış olan 200 m'lik akarsu bölümlerinde, teorik ve pratik eğitim almış personel tarafından akıntıya karşı gidilerek yapılmıştır. Avlama işleminin akıntıya karşı yapılması, temiz suda avlanma olanağı sağlamıştır (Halyk ve Balon 1983; Peterson ve Cederholm 1984; Coles vd. 1985). Bütün örnekleme tarihlerinde ve istasyonlarında 1,30 saat süreyle avlama yapılmıştır. Araştırma süresince anot ve katodun aynı şahıslar tarafindan kullanılmasına özel itina gösterilmiştir. Avlamada, anodu kullanan bir kişi ile balık kepçesini kullanan iki kişi yan yana yürümüşler, diğer bir kişi de katodu kullanmış ve iki kutup arasında meydana gelen elektiriki alanda bayılan balıklar kepçelerle toplanmıştır (Penczak vd. 1981). Herbir örnekleme istasyonunda avlanan balıklar MS 222 anestezik madde bulunan 40 L'lik plastik kaplara yerleştirilmiştir. Uygulanan anestesi sonucunda balıklarda ölüm gözlemlenmemiştir. Avlanan balıklar türlerine göre ayrılmış, sayılmış ve Gıda, Tarım ve Hayvancılık Bakanlığı'ndan alınan izne göre, canlı olarak suya iade edilmiştir. $\mathrm{Bu}$ işlemler bütün örnekleme istasyonlarında tekrarlanmıştır.

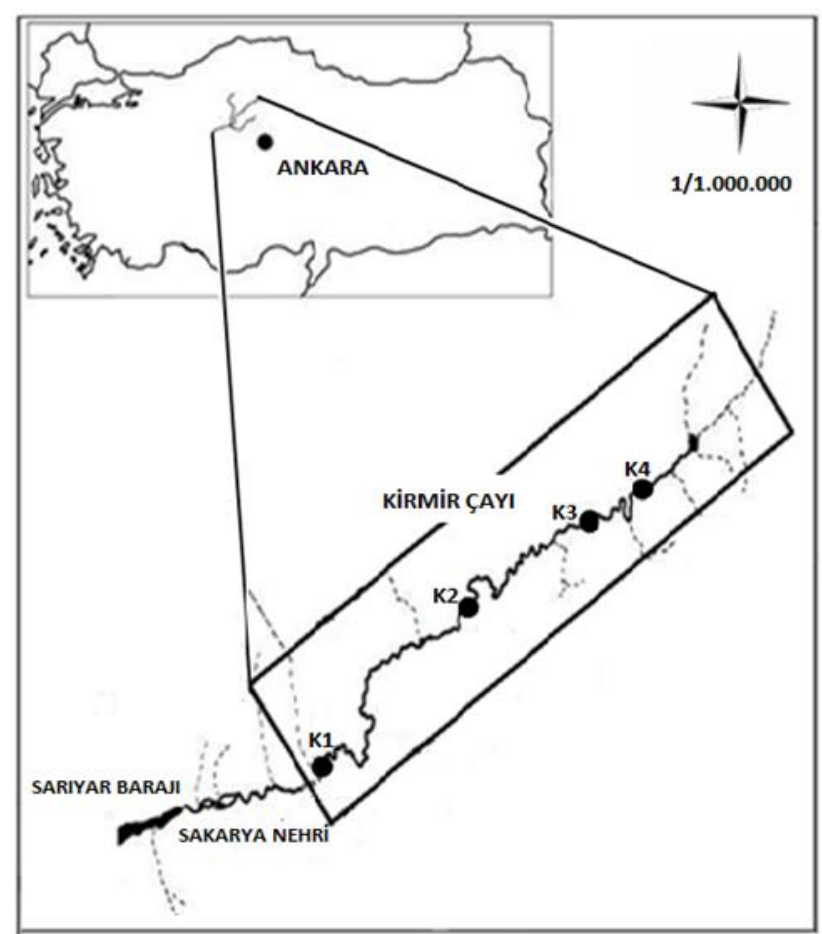

Şekil 1. Araştırma alanı ve örnekleme istasyonlarının konumu 
Balık türlerinin tanımlanmasında Kuru (2004), Geldiay ve Balık (2007), Kottelat ve Freyhof (2007), Fricke vd. (2007) ve Turan vd. (2009)'dan yararlanılmıştır. Balıkların biyoçeşitlilik indekslerinin hesaplanmasinda Shannon-Wiener çeşitlilik indeksi $\left(H^{\prime}\right)$; Simpson çesitlilik indeksi (1$D)$; Shannon-Wiener çeşitlilik indeksine dayalı eşitlik indeksi $\left(J^{\prime}\right)$; Simpson indeksine dayalı eşitlik indeksi $\left(V^{\prime}\right)$ ve Simpson baskınlı indeksi $(D)$ kullanılmıştır (Krebs 1998; Kwak ve Peterson 2007).

Shannon-Weiner çeşitlilik indeksi $\left(H^{\prime}\right)$;

$$
H^{\prime}=-\sum_{i=1}^{s} p_{i} \log _{e} p_{i}
$$

formülü ile hesaplanmıştır. Burada; $H^{\prime}$ ShannonWeiner çeşitlilik indeksinin değerini, $p_{i}$ (nispi bolluk) $i$ balık türünün populasyondaki oranını, $S$ (tür zenginliği) topluluktaki tür sayısını, $\log _{e} p_{i}$ 'nin doğal logaritmasını ifade etmektedir.

Simpson çesitlilik indeksi (1-D);

$$
D=\sum_{i=1}^{S} p_{i}^{2}
$$

eşitliğinden bulunmuştur. Burada; $D$ Simpson çeşitlilik miktarını, 1-D Simpson çeşitlilik indeksinin değerini, $p_{i}$ (nispi bolluk) $i$ balık türünün populasyondaki oranını, $S$ (tür zenginliği) topluluktaki tür sayısını belirtmektedir.

Shannon-Weiner çeşitlilik indeksine dayalı eşitlik indeksi $\left(J^{\prime}\right)$;

$$
J^{\prime}=H^{\prime} / H_{\text {mak }}^{\prime}=H^{\prime} / \log _{e} S
$$

şeklinde hesaplanmıştır. Burada; $J^{\prime}$ Shannon-Weiner çeşitlilik indeksine dayalı eşitlik indeksinin değerini, $H^{\prime}$ Shannon-Weiner çeşitlilik indeksinin değerini,

$$
H_{\text {mak }}^{\prime}=\log _{e} S
$$

Shannon-Weiner çeşitlilik indeksinin maksimum değerini, $S$ (tür zenginliği) topluluktaki tür sayısını göstermektedir.

Simpson indeksine dayalı eşitlik indeksi $\left(V^{\prime}\right)$;

$$
V^{\prime}=1-D / 1-1 / S
$$

eşitliğinden hesaplanmıştır. Burada; $V$ ' Simpson indeksine dayalı eşitlik indeksinin değerini, 1-D Simpson çeşitlilik indeksinin değerini, $S$ (tür zenginliği) topluluktaki tür sayısını belirtmektedir.

Simpson baskınlık İndeksi $(D)$;

$$
D_{2}=\sum_{i=1}^{2} p_{i}
$$

formülü ile bulunmuştur. Burada; $D_{2}$ populasyon içerisindeki en yoğun olan iki türün baskınlık indeksinin değerini, $p_{i}$ (nispi bolluk) $i$ balık türünün populasyondaki oranını belirtmektedir. İstasyonlara ve mevsimlere göre elde edilen indeks değerleri arasındaki farklılıklar, tek yönlü varyans analiziyle (ANOVA) kontrol edilmiştir. Bütün istatistiksel kontroller SPSS-17 paket programı yardımıyla yapılmış ve güven seviyesi $\alpha=0,05$ olarak alınmıştır.

\section{Bulgular}

Kirmir Çayı'nda Kasım 2006 - Kasım 2007 döneminde gerçekleştirilen örneklemelerde toplam 4175 balık avlanmıştır. Örneklemelerde 3 familyaya (Cyprinidae, Cobitidae ve Balitoridae) ait 9 tür belirlenmiştir (Çizelge 1). A. escherichii toplam popülasyon içerisinde \% 28,71 ile en çok; $C$. simplicispina ise \% 0,43 ile en en az bulunan türler olmuştur (Şekil 2).

Çizelge 1 Kirmir Çayı'nda avlanan balık türleri, türlere göre birey sayısı (N) ve birey sayısının toplam populasyona oranı $(\% \mathrm{~N})$.

\begin{tabular}{llcc}
\hline Familya & Balık Türleri & $\mathrm{N}$ & $\% \mathrm{~N}$ \\
\hline & Tatlısu kefali (S. pursakensis Hankó, 1925) & 454 & 10,87 \\
& Bıyıklı balık (B. escherichii Heckel, 1843) & 584 & 13,99 \\
& Siraz (C.baliki Turan, Kottelat, Ekmekçi and Imamoğlu, 2006) & 1173 & 28,10 \\
Cyprinidae & Saçaklı siraz (C. sieboldii Steindachner, 1864) & 65 & 1,56 \\
& Noktalı inci balı̆̆ (A. bipunctatus Bloch, 1782) & 322 & 7,71 \\
& Kababurun (C. angorense Elvira, 1987) & 245 & 5,87 \\
& Sakarya incisi (A. escherichii Steindachner, 1897) & 1199 & 28,72 \\
Cobitidae & Taşyiyen balı̆̆ (C. simplicispina Hankó, 1925) & 18 & 0,43 \\
Balitoridae & Çamur balı̆ı̆ (O. angorae Steindachner, 1897) & 115 & 2,75 \\
\hline TOPLAM & & 4175 & 100 \\
\hline
\end{tabular}




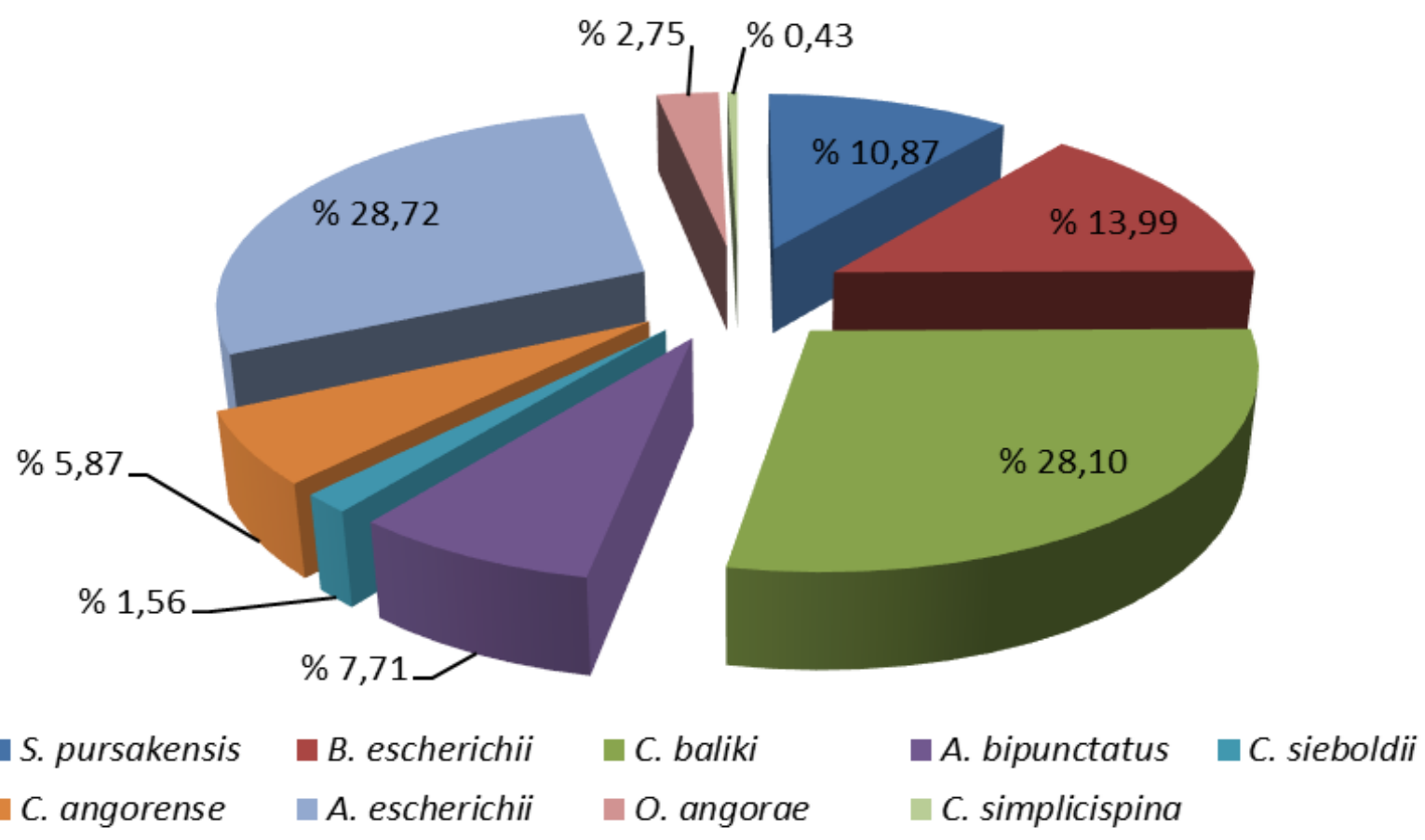

Şekil 2. Kirmir Çayı balık türlerinin dağılımı.

Kirmir Çayı'nda Kasım 2006 - Kasım 2007 döneminde 4 örnekleme istasyonunda yapılan avlamalara dayalı olarak çeşitlilik indeksleri hesaplanmış ve Çizelge 2'de verilmiştir. Tür çeşitliliği ve türlerin birey sayılarının homojen bir şekilde dağılımı ile doğru orantılı olarak artan Shannon-Wiener çeşitlilik indeksi $\left(H^{\prime}\right)$, örnekleme istasyonlarına göre 1,52-1,80 arasında değişmiştir. Shannon-Wiener çeşitlilik indeksinin 4. örnekleme istasyonunda diğer örnekleme istasyonlarına göre daha küçük çıkması, bu örnekleme istasyonundaki türlerin eşit dağılım göstermemesi, A. escherichii türünün baskın olması ve örnekleme istasyonunun diğer örnekleme istasyonlarına göre durgun ve derin olmasından kaynaklanmıştır. Türlerin genel olarak homojen dağılım gösterdiği 2. örnekleme istasyonunda indeks değeri yüksek çıkmıştır. Ancak örnekleme istasyonları arasında Shannon-Wiener çeşitlilik indeksi bakımından gözlenen farklılıklar örnekleme istasyonlarının dip yapısı ve bankların durumundan kaynaklanmıştır $(\mathrm{F}=0,145, \mathrm{p}>0,05)$.

Bir toplulukta bulunan türler arasinda bolluğun ne kadar eşit bir miktarda dağıldığını gösteren ölçüt olan, Shannon-Wiener çeşitlilik indeksine dayalı eşitlik indeksi $\left(J^{\prime}\right)$ 'nin Kirmir Çayı'nda örnekleme istasyonlarına göre 0,69-0,82 arasında değiştiği saptanmış ve örnekleme istasyonları arasında gözlenen farklılıkların önemli olmadiğ $1(\mathrm{~F}=0,214, \mathrm{p}>0,05)$ ve ortalama $0,77 \pm 0,06$ olduğu bulunmuştur. Bir örnekten rastgele seçilen iki adet bireyin farklı olma olasılığını gösteren ve $0-1$ arasında değișen değerler alan Simpson çeşitlilik indeksi (1-D), en düşük 4. örnekleme istasyonu $(0,72)$, en yüksek $(0,79)$ ise 1 . ve 2 . örnekleme istasyonları için hesaplanmış $(\mathrm{F}=0,077$, $p>0,05$ ) ve ortalama $0,76 \pm 0,03$ bulunmuştur.

Simpson indeksine dayalı eşitlik indeksi ( $\left.V^{\prime}\right)$ 'nin örnekleme istasyonlarına göre 0,81-0,89 arasında değiștiği $(\mathrm{F}=0,153, \quad \mathrm{p}>0,05) \quad$ ve ortalama $0,86 \pm 0,04$ olduğu saptanmıştır. Simpson baskınlık indeksi $(D)$ ise örnekleme istasyonlarına göre 0,54-0,71 arasında değişmiş ve ortalama $0,61 \pm 0,07$ olarak belirlenmiştir.

Mevsimlere göre en yüksek Shannon-Wiener çeşitlilik indeks $\left(H^{\prime}\right)$ değeri; sonbahar (Kasım-2007) (1,65), Shannon-Wiener çeşitlilik indeksine dayalı eşitlik indeks $\left(J^{\prime}\right)$ değeri; 2007 yılı yaz ve sonbahar $(0,83)$, Simpson çeşitlilik indeks (1-D) değeri; sonbahar (Kasım-2006) (0,76), Simpson indeksine dayalı eşitlik indeks $\left(V^{\prime}\right)$ değeri; 2006 ve 2007 y1l sonbahar ve 2007 y1lı yaz $(0,88)$ ve Simpson baskınlık indeks $(D)$ değeri 2007 yılı kış mevsiminde kaydedilmiştir. Mevsimlere göre çeşitlilik indeksleri arasında gözlenen farklılıklar istatistik açıdan önemli bulunmamıştır (p>0,05) (Çizelge 3). 
Çizelge 2. Kirmir Çayı balık türlerinin istasyonlara göre çeşitlilik indeksleri.

\begin{tabular}{|c|c|c|c|c|c|}
\hline \multirow{2}{*}{ Çeşitlilik İndeksleri } & \multicolumn{4}{|c|}{ Örnekleme İstasyonları } & \multirow{2}{*}{ Ortalama } \\
\hline & 1 & 2 & 3 & 4 & \\
\hline \multicolumn{6}{|l|}{ Çeşitlilik } \\
\hline Tür & 9 & 9 & 8 & 9 & \\
\hline Familya & 2 & 2 & 1 & 2 & \\
\hline Shannon-Wiener Çeşitlilik İndeksi $\left(H^{\prime}\right)$ & 1,73 & 1,80 & 1,64 & 1,52 & $1,67 \pm 0,12$ \\
\hline Shannon-Wiener Çeşitlilik İndeksine Dayalı Eşitlik İndeksi $\left(J^{\prime}\right)$ & 0,79 & 0,82 & 0,79 & 0,69 & $0,77 \pm 0,06$ \\
\hline Simpson Çesitlilik İndeksi $(1-D)$ & 0,79 & 0,79 & 0,75 & 0,72 & $0,76 \pm 0,03$ \\
\hline Simpson İndeksine Dayalı Eşitlik İndeksi $\left(V^{\prime}\right)$ & 0,89 & 0,89 & 0,86 & 0,81 & $0,86 \pm 0,04$ \\
\hline Simpson Baskınlık İndeksi $(D)$ & 0,54 & 0,58 & 0,59 & 0,71 & $0,61 \pm 0,07$ \\
\hline
\end{tabular}

Çizelge 3. Kirmir Çayı balık türlerinin mevsimsel çeşitlilik indeksleri

\begin{tabular}{lccccc}
\hline Örnekleme Zamanı & $H^{\prime}$ & $J^{\prime}$ & $1-D$ & $V^{\prime}$ & $D$ \\
\hline Sonbahar (Kasım 2006) & $1,63 \pm 0,09$ & $0,81 \pm 0,02$ & $0,76 \pm 0,04$ & $0,88 \pm 0,04$ & $0,59 \pm 0,09$ \\
Kiş (Şubat 2007) & $1,54 \pm 0,09$ & $0,74 \pm 0,04$ & $0,73 \pm 0,04$ & $0,83 \pm 0,04$ & $0,65 \pm 0,08$ \\
İlkbahar (Mayıs 2007) & $1,55 \pm 0,29$ & $0,77 \pm 0,08$ & $0,72 \pm 0,09$ & $0,83 \pm 0,08$ & $0,60 \pm 0,08$ \\
Yaz (Ağustos 2007) & $1,59 \pm 0,10$ & $0,83 \pm 0,03$ & $0,75 \pm 0,04$ & $0,88 \pm 0,04$ & $0,60 \pm 0,05$ \\
Sonbahar (Kasım 2007) & $1,65 \pm 0,17$ & $0,83 \pm 0,05$ & $0,75 \pm 0,04$ & $0,88 \pm 0,04$ & $0,61 \pm 0,04$ \\
\hline \multirow{2}{*}{ ANOVA } & $\mathrm{F}=0,294$ & $\mathrm{~F}=2,779$ & $\mathrm{~F}=0,518$ & $\mathrm{~F}=1,067$ & $\mathrm{~F}=0,354$ \\
& $\mathrm{p}>0,05$ & $\mathrm{p}>0,05$ & $\mathrm{p}>0,05$ & $\mathrm{p}>0,05$ & $\mathrm{p}>0,05$ \\
\hline
\end{tabular}

\section{Tartışma ve Sonuç}

Elde edilen verilere göre, $A$. escherichii ve C. baliki en yoğun bulunan türlerdir (\% 28,72 ve $\%$ 28,10). Okur ve Özdilek (2008) Amanos Dağları içerindeki bazı çaylarda (Hatay) yaptıkları çalışmada; popülasyon içerisinde Capoeta barroisi $\% 42,2$ ve A. escherichii \% 4,6' 11k bir dağılım göstermiştir. Korkmaz ve Zencir (2009) ise Kirmir Çayı'nın kolu olan Süveri Çayı'nda C. baliki \% 77,96, A. escherichii ise $\% 8,9$ olarak dağılım gösterdiğini bildirmiştir. Tatlısularda örnekleme istasyonlarının habitat yapısından ve abiyotik-biyotik faktörlerin değişken olmasından dolayı türlerin sayısı ve yoğunluğu arasındaki farklılıkların karşılaştırılması zordur (Vlach vd. 2005). Bu çalışmada elde edilen değerler $C$. baliki ile benzerlik gösterirken; A. escherichii dağglımı yüksek bulunmuştur. Bu farklılığın A. escherichii'nin kötü çevresel koşullara karşı daha toleranslı olmasının yanı sıra küçük çaylara göre büyük rrmakların daha fazla miktarda balık yoğunluğuna sahip olmasından kaynaklandığ düşünülebilir.

Shannon-Wiener çeşitlilik indeksi $\left(H^{\prime}\right)$, tür çeşitliliğini ve eşitliğini birleştiren bir değerdirki; bu indeks >3,99 olduğunda etkisiz; 3-3,99 arasinda olduğunda çok az etkili; 2-2,99 olduğu zaman orta derecede etkili ve $<2$ olduğunda ise ciddi olarak etkilidir (Namin ve Spurny 2004). Bu kategoriye dayalı olarak Kirmir Çayı'nda çalışılan örnekleme istasyonlarının çevresel faktörlerden ciddi şekilde etkilendiği sonucu çıkmaktadır. Okur ve Özdilek (2008) Amonos Dağları içerindeki bazı çaylarda (Hatay), Korkmaz ve Zencir (2009) Kirmir Çayı'nın kolu olan Süveri Çayı'nda elde edilen ShannonWiener çeşitlilik indeks $\left(H^{\prime}\right)$ değerleri (sırasıyla $0,28-0,61,0,55-1,04)$ bu çalışmada elde edilen değerlerden $(1,52-1,80)$ düşük olduğu tespit edilmiştir. Shannon-Wiener çeşitlilik indeks $\left(H^{\prime}\right)^{\prime}$ 'nin yüksek çıkmasının, Kirmir Çayı balık türlerinin genel olarak homojen dağılım göstermesinden kaynaklandığı düşünülmektedir. Ayrıca balık türlerinin çeşitliğini; insan aktiviteleri, suyun fizikokimyasal özellikleri, topografya, su derinliği, balığın habitat tercihleri ve ortamın besin durumu gibi farkl111klar da etkilemektedir (Rumeaida vd. 2014).

Shannon-Wiener çeşitlilik indeksine dayalı eşitlik indeksi $\left(J^{\prime}\right)$; örnekleme istasyonlarındaki türler arasında birey sayılarının dağılımını, düzenliliğini ve homojenliğini gösterdiğinden, topluluk içinde az sayıda baskın türlerin varlığı bu indeks değerini önemli oranda düşürmektedir. Değerin 1'e yakın çıkması düzenli, sıfıra yakın çıkması ise düzensiz dağıldığını göstermektedir (Jorgensen vd. 2005). Bu bağlamda Kirmir Çayı'ndaki balık popülasyonlarının dağılımının homojen olduğu sonucu çıkmaktadır. Korkmaz ve Zencir (2009) tarafindan saptanan Shannon-Wiener çeşitlilik indeksine dayalı eşitlik indeks $\left(J^{\prime}\right)$ değeri $(0,39)$ bu çalışmada kaydedilen 
değerin $(0,77)$ yaklaşık yarısıdır. Bu farklılığın abiyotik ve biyotik faktörlerden kaynaklandığı, ayrıca çalışma ortamında taşyiyen balığ (C. simplicispina Hankó, 1925) ve çamur balığ 1 (O. angorae Steindachner, 1897) gibi türlerin yoğunluğunun az olmasinın Shannon-Wiener çeşitlilik indeksine dayalı eşitlik indeks $\left(J^{\prime}\right)$ değerinin düşük çıkmasına neden olduğu düşünülebilir.

$\mathrm{Bu}$ çalışmada istasyonlara ve mevsimlere göre saptanan Simpson baskınlık indeksi $(D)$ değerlerinin genellikle sıfira yakın olması, Kirmir Çayı'nda az sayıda baskın türlerin olduğunu, tür çeşitliliğinin ise yüksek olduğunu göstermektedir. Simpson çesitlilik indeksi $(1-D)$ ise 1'e yakın değerler aldığından Kirmir Çayı'nda tür sayısının fazla olduğuna işaret etmektedir.

Sonuç olarak, Dünya Doğayı Koruma Birliği'nin (IUCN) 2014 y1l1 Kırmız1 Listesi'ne göre, $S$. pursakensis, A. escherichii ve $O$. angorae asgari endişe (LC), B. escherichii ve $C$. sieboldii tehlike altında (EN), A. bipunctatus hassas (VU) ve $C$. angorense ve $C$. simplicispina ise kritik derecede tehlike altında (CR) türler olarak tespit edilmiștir (IUCN 2014). Bu bağlamda, Kirmir Çayı'nda türlerin devamlılığını tehdit eden en önemli unsurların çevresel kirlilik, tarımsal kirlilik, metal kirliliği, habitat kaybı ve kuraklık olduğu düşünülmektedir.

\section{Teșekkür}

$\mathrm{Bu}$ çalışma; 2008 yılında Ankara Üniversitesi Fen Bilimleri Enstitüsü Su Ürünleri Anabilim Dalı'na sunulan "Kirmir Çayı ve kollarındaki balık populasyonlarında yoğunluk, biyomas ve üretimin tahmini" başl1klı doktora tezinden üretilmiş ve 1-4 Eylül 2015 tarihinde, İzmir'de düzenlenen 18.Ulusal $\mathrm{Su}$ Ürünleri Sempozyumu'nda poster bildiri olarak sunulmuştur.

\section{Kaynaklar}

Benzer S. 2013. Age and growth of chub (Squalius cephalus (L., 1758)) population in Kirmir Stream of Sakarya River, Turkey. Indian J Anim Res. 47(6):538-542.

Bohlin T, Hamrin S, Heggberget TG, Rasmussen G, Saltveit SJ. 1989. Electrofishing theory and practice with special emphasis on salmonids. Hydrobiologia. 173(1):9-43. doi: $10.1007 / \mathrm{BF} 00008596$.

Coles TF, Wortley JS, Noble P. 1985. Survey methodology for fish population assessment within anglian water. J Fish Biol. 27 (Supplement A): 175-186.

doi: 10.1111/j.1095-8649.1985.tb03240.x

Erten S. 2004. Uluslararası düzeyde yükselen bir değer olarak biyolojik çesitlilik. Hacet Üni Eğit Fak Derg. 27:1-10.
Fricke R, Bilecenoğlu M, Sarı HM. 2007. Annotated checklist of fish and lamprey species (Gnathostomata and Petromyzontomorphi) of Turkey, including a Red List of threatened and declining species. Stuttgarter Beitr Naturk. Ser. A(706):1-169.

Geldiay R, Balık S. 2007. Türkiye tatlısu balıkları. Ege Üniversitesi Basımevi, Bornava-İzmir, $638 \mathrm{~s}$.

Gülsoy S, Özkan K. 2008. Tür çeşitliliğinin ekolojik açıdan önemi ve kullanılan bazı indisler. Süleyman Demirel Üni Orman Fak Derg. Ser. A(1):168-178.

Halyk LC, Balon EK. 1983. Structure and ecological production of the fish taxocene of a small floodplain system. Can J Zoolog. 61(11):2446-2464. doi: 10.1139/z83-326.

Hankin DG. 1984. Multistage sampling designs in fisheries research: Applications in small streams. Can J Fish Aquat Sci. 41(11):1575-1591. doi: 10.1139/f84-196.

IUCN 2014. The IUCN Red List of Threatened Species. Gland, Switzerland: IUCN database; [cited 2016 Nov18]. Available form http://www.iucnredlist.org/search

Jorgensen SE, Costanse R, Xu Fu-Liu. 2005. Handbook of ecological indicators for assessment of ecosystem health. Taylor and Francis Group Eddition, London, $439 \mathrm{p}$.

Kahraman AE, Göktürk D, Aydın E. 2014. Length-weight relationships of five fish species from the Sakarya River, Turkey. Annu Res Rev Biol. 4(15):2476-248. doi: 10.9734/ARRB/2014/7513

Korkmaz AŞ, Zencir Ö. 2009. Fish community structure in Suveri Stream, Central Anatolia, Turkey. J Anim Vet Adv. 8 (11):2305-2310.

Kottelat M, Freyhof J. 2007. Handbook of European freshwater fishes. Publications Kottelat, Cornol, Switzerland, 646p.

Krebs CJ. 1998. Ecological methodology. In: Fogarty E, McDougal V, Murray N, editor(s). 2nd ed. California: British California University Press. 624 p.

Kuru M. 2004. Recent systematic status of inland water fishes of Turkey. Gazi Üni Eğit Fak Derg. 24(3):1-21.

Küçük S, Alpbaz A. 2008. The impact of organic pollution on the Kirmir Creek and Sakarya River in Turkey. Water Resour. 35(5):617-624. doi:10.1134/S0097807808050102.

Kwak TJ, Peterson, JT. 2007. Community indices, parameters, and comparisons. In: Guy C S. and Brown M L, editor(s). Analysis and interpretation of freshwater fisheries data. Bethesda (Maryland): Am Fish S. p. 677-763.

Namin JI, Spurny P. 2004. Fish community structure of the middle course of the Bečva River. Czech J Anim Sci. 49 (1):43-50.

Odum EP, Barrett GW. 2005. Ekoloji'nin temel ilkeleri. In: Isık K, çeviri editörü. Ankara: Palme Yayıncılık, $598 \mathrm{~s}$.

Okur E, Özdilek SY. 2008. Preliminary study of fish community structure in Amanos mountain streams (Hatay-Turkey). Biologia, 63(3):427-438. doi: 10.2478/s11756-008-0058-3. 
Ölmez M. 1992. Yukarı Sakarya Havzası Sakaryabaşı Bölgesi balıklarının populasyon dinamiği üzerinde bir araştırma. [Doktora tezi]. Ankara Üniversitesi. $228 \mathrm{~s}$.

Penczak T, Zalewski M, Suszycka E, Molinski M. 1981. Estimation of the density, biomass and gowth rate of fish populations in two small lowland rivers. Ekol Pol. 29(2): 233-255.

Peterson NP, Cederholm CJ. 1984. A comparison of the removal and mark-recapture methods of population estimation for juvenile coho salmon in a small stream. N Am J Fish Manage. 4(1):99-102. doi:10.1577/1548-8659(1984)4<99:ACOTRA>2.0.CO;2.

Rumeaida MP, Daud SMM, Badri FMI. 2014. Fish diversity and abundance in Bidong Island, South China Sea, Malaysia. AACL Bioflux. 7 (3):176-183.

Solak K, Gül A, Yılmaz M. 1995. Kirmir Çayı' nda yaşayan tatlısu kefali Leuciscus cephalus
(Lin.,1758)' un büyüme performansları üzerine bir araştırma. Süleyman Demirel Üni Eğirdir Su Ürün Derg. 4:49-62.

Turan D, Yllmaz BT, Kaya C. 2009. Squalius kottelati, a new cyprinid species (Teleostei: Cyprinidae) from Orontes River Turkey. Zootaxa. 2270:53-62. doi: 10.5281/zenodo. 190947

Vlach P, Dusek J, Svatora M, Moravec P. 2005. Fish assemblage structure, habitat and microhabitat preference of five fish species in a small Stream. Folia Zool. 54 (4): 421-431.

Yilmaz M, Gül A, Solak K. 1996. Sakarya Nehri Kirmir Çayı'nda yaşayan in balığı Capoeta tinca (Heckel, 1843)'nı bazı biyolojik özelliklerinin incelenmesi. Turk J Zool. 20 (3): 349-356. 